\title{
Hypoglycemia after bariatric surgery: importance of exhaustive hormonal study
}

\author{
Alejandra Perez-Montes de Oca ${ }^{\circledR 1}$, Silvia Pellitero' ${ }^{1}$ and Manel Puig-Domingo ${ }^{1}$ \\ ${ }^{1}$ Endocrinology and Nutrition, Hospital Universitari Germans Trias I Pujol, Badalona, Spain
}

Correspondence should be addressed to A Pérez-Montes de Oca Email alec148@gmail.com

\section{Summary}

Hypoglycemia is an uncommon clinical problem in non-diabetic patients or patients not being treated for diabetes mellitus. It is a rare, but well-established complication of bariatric surgery and, in some cases, it can be the only symptom of another medical problem. A 50-year-old woman with a history of partially recovered hypopituitarism after transsphenoidal surgery for a non-functioning pituitary macroadenoma complained about symptomatic hypoglycemia after sleeve gastrectomy surgery. Our initial studies failed to determine the cause for these episodes and treatment with acarbose (suspecting a dumping syndrome) was not helpful. Finally, laboratory findings revealed growth hormone (GH) deficiency. The patient received treatment with GH, with the resolution of symptoms after 3 months of treatment. Our case suggests that all causes of hypoglycemia should be considered and studied after bariatric surgery. An improvement in insulin-resistance following bariatric surgery can trigger clinical manifestations of GH deficiency.

\section{Learning points:}

- Postprandial hypoglycemia after bariatric surgery is usually due to dumping syndrome.

- Even after bariatric surgery, all causes of hypoglycemia should be considered and studied.

- After significant weight loss, insulin sensitivity is usually restored and can trigger clinical manifestations of GH deficiency.

- Hypoglycemia is a rare symptom of GH deficiency.

\section{Case presentation}

A 50-year-old woman was evaluated in our center for morbid obesity and was treated with sleeve gastrectomy (SG) in 2013. She had sleep apnea, hypertension, diettreated type 2 diabetes mellitus (T2DM) and dyslipidemia. Most of these comorbidities, including T2DM, resolved after weight loss 1 year after SG. In addition, she had a history of a non-functioning pituitary macroadenoma treated with transsphenoidal surgery (TSS) in 2009 with preoperative secondary gonadotropin and GH deficiencies, although the last latter recovered after transsphenoidal surgery. In a follow-up visit, 1 year after bariatric surgery, she reported symptomatic hypoglycemia with glucose levels of 50-60 mg/dL. These episodes occurred either fasting or after meals.

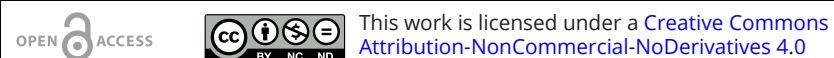
International License.
}

In 2016, conversion to gastric bypass (GB) was undertaken due to severe gastroesophageal reflux. As the patient kept losing weight (34 kg since SG), hypoglycemic episodes progressed, with levels below $40 \mathrm{mg} / \mathrm{dl}$, including an episode of loss of consciousness.

\section{Investigation}

We performed a diagnostic work-up for hypoglycemia, with the initial aim of confirming the suspicion that it would probably be related to the SG. In light of her history of hypopituitarism, a hormonal evaluation was also performed. The initial study showed normal basal insulin, cortisol, GH, insulin-like growth factor 1 (IGF-1) (c) 2021 The authors
https://edm.bioscientifica.com/
Published by Bioscientifica Ltd Downloaded from Bioscientifica.com at 04/26/2023 09:33:14AM 
and corticotropin (ACTH) levels, as well as a normal response of cortisol levels after ACTH stimulation (Table 1). Continuous glucose monitoring (GCM) for 1 week demonstrated $47 \%$ of the time in hypoglycemia after every meal, between meals and during sleep (Fig. 1), while the patient was following a low carbohydrate diet (less than $1200 \mathrm{kcal})$. In light of suspected dumping syndrome, we started treatment with acarbose $500 \mathrm{mg}$ TID, but no changes in the symptomatology or the frequency of the episodes were evident. We then performed a 72-h fast test to exclude other causes of hypoglycemia, resulting in nadir blood glucose levels of $55 \mathrm{mg} / \mathrm{dl}$. At that moment, the study of GH (basal) and cortisol axis (basal and after stimulation) were normal.

In 2016, laboratory testing revealed a low IGF1 with a failed response to a glucagon test (Table 2).

\section{Treatment}

We concluded that the hypoglycemia was secondary to a GH deficiency. The patient started treatment with GH 0.2 mg daily with a good response.

\section{Outcome and follow-up}

Hypoglycemic episodes completely reversed after 3 months of treatment in association with normalized values of GH, IGF-1 and insulin levels. Two years after starting $\mathrm{GH}$ treatment the patient remains asymptomatic.

\section{Discussion}

Historically, hypoglycemia causes in non-diabetic patients are categorized based on the symptomatology and its relationship with meals. Once the Whipple's Triad (symptoms of hypoglycemia, blood glucose level $<50 \mathrm{mg} / \mathrm{dL}$, and relief of symptoms following ingestion of glucose) is established, it requires evaluation with a detailed medical history and laboratory testing $(1,2)$. In this case, we assessed the patient as non-diabetic as she had been previously diagnosed with T2DM, which reversed after SG. She had at least two predisposing disorders that could lead to hypoglycemia, such as bariatric surgery and a previous diagnosis of asymptomatic GH deficiency that recovered after TSS surgery.

Hypoglycemia is a complication of bariatric surgery and the most common cause is postprandial hypoglycemia in the context of dumping syndrome (3). It occurs early in the postoperative course and usually improves with meals frequency and content modification and in some cases, pharmacotherapy $(4,5)$. Our patient had normal insulin levels after the SG; CGM data revealed that the episodes were not related to meals and did not respond to acarbose therapy, making the diagnosis of dumping syndrome secondary to SG less likely. In patients who had bariatric surgery, the use of CGM as a diagnosing method is controversial due to a lower accuracy for low glycemic levels, but it has been reported to detect more true hypoglycemia events than other procedures (6);

Table 1 Hormonal profile before and after bariatric surgeries.

\begin{tabular}{|c|c|c|c|c|c|}
\hline & Normal range & Before SG (Nov 2012) & Initial study' (June 2014) & $\overline{\text { Before GB (Oct 2015) }}$ & After GB (July 2016) \\
\hline $\mathrm{GH}(\mu \mathrm{g} / \mathrm{L})$ & $0.05-8.0$ & 0.06 & 0.28 & 0.82 & 0.68 \\
\hline IGF-1 (ng/mL) & $62-243$ & 73.1 & 67.9 & 64.9 & 37.7 \\
\hline IGF-1 S.D. & -2 to +2 & - & -1.69 & -1.68 & -2.68 \\
\hline ACTH $(p g / m L)$ & $5.0-46$ & 21.4 & 11.5 & 10.8 & 12.3 \\
\hline Cortisol ( $\mu g / d L)$ & $6.2-19.4$ & 23.9 & 17.1 & 15.2 & 16.4 \\
\hline $\mathrm{FSH}^{*}(\mathrm{U} / \mathrm{L})$ & $7.7-58.5$ & 4.56 & 4.92 & 5.37 & 5.53 \\
\hline $\mathrm{LH}^{*}(\mathrm{U} / \mathrm{L})$ & $25.8-134$ & 2.59 & 2.63 & 2.35 & 1.94 \\
\hline TSH $(\mu \mathrm{Ul} / \mathrm{mL})$ & $0.27-4.2$ & 3.05 & 1.53 & 2.26 & 1.99 \\
\hline FT4 (ng/dL) & $0.82-1.77$ & 1.27 & 1.05 & 1.33 & 1.04 \\
\hline Insulin (mIU/L) & $2.7-24$ & 73 & 8.5 & 9.3 & 8 \\
\hline HOMA-IR** & & 26 & 1.4 & 1.5 & 1.4 \\
\hline C-peptide (ng/mL) & $0.8-5.2$ & 11.6 & 3.3 & - & 2.4 \\
\hline $\begin{array}{l}\text { Cortisol after ACTH } \\
\text { stimulation*** }(\mu g / d L)\end{array}$ & $>18$ & - & 28 & 25 & - \\
\hline Weight (kgs)/BMI (kg/m²) & & $123 / 40.62$ & $89.1 / 29.5$ & $99 / 32.69$ & $85.5 / 28.2$ \\
\hline
\end{tabular}




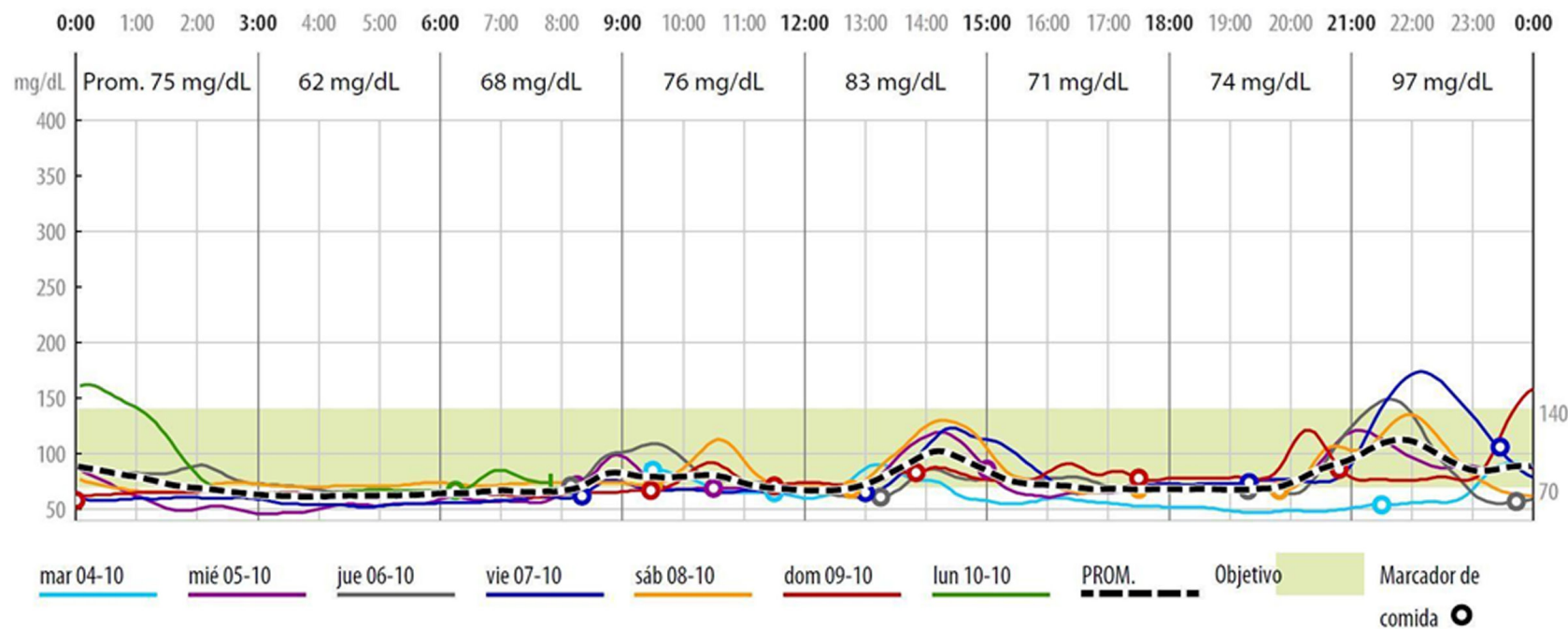

Figure 1

Glucose monitoring system data of the patient. The foods are marked with a circle.

thus it can be useful to document the chronology of the episodes.

On the other hand, our patient had documented hypopituitarism due to a non-functioning macroadenoma and the hormonal assessments for the first years after neurosurgery only revealed a gonadotropin deficiency with a low end normal basal GH, suggesting that she had partially recovered this deficiency after TSS, although a stimulation test was not performed at this that time. Up to $50 \%$ of patients recover at least one pituitary hormone that has been deficient after TSS surgery; GH is less likely to recover than gonadotropins, ACTH, and TSH (7).

A year after SG surgery, when the patient had lost $34 \mathrm{~kg}$ and when the $\mathrm{GH}$ axis was at the lower end of normal (Table 1), is when the hypoglycemic episodes commenced, probably due to restored insulin sensitivity (Fig. 2). Increased insulin sensitivity or remission of T2DM has long been noted in patients who have undergone bariatric surgery (8) and after an important weight loss in an obese patient, GH deficiency can become symptomatic when insulin sensitivity is restored. As a way to measure insulin resistance (IR), homeostatic model assessment for
IR (HOMA-IR) was used as it has proved to be a robust tool for this assessment and is the most widely used index of IR in large population studies. However, its cut-off values differ for different aspects such as age and race $(8,9)$. For our patient, a threshold value of 2.3 was used (8) and measured values went from 26 before SG to 1.4 after the surgery, suggesting a remission of her IR (Fig. 2).

It is also important to take into account that obese patients have an impaired somatotropin response to hypoglycemia, as well as GH hyposecretion and hypogonadism, which are mostly reversed after sustained weight loss by bariatric surgery, with the restoration of a normal spontaneous and stimulated GH release (10, 11). In our patient, the hypogonadism persisted and hypoglycemia episodes worsened as the patient loses lost weight, making evident that the deficiencies were not obese-related and that GH deficiency was asymptomatic due to insulin resistance.

GH deficiency of the adult is a well-defined condition with several signs and symptoms that are usually nonspecific; hypoglycemia is a rare one. Establishing an accurate diagnosis may be challenging and it requires

Table 2 Glucagon stimulation test.

\begin{tabular}{lcc} 
& & $\mathbf{- 1 5}$ min \\
\cline { 1 - 1 } Glucose $(\mathrm{mg} / \mathrm{dL})$ & 72 \\
Cortisol $(\mu \mathrm{g} / \mathrm{dL})$ & & 15.6 \\
$\mathrm{GH}(\mathrm{ng} / \mathrm{mL})$ & 0.48 \\
\hline
\end{tabular}

\begin{tabular}{c}
\hline Basal \\
\hline 74 \\
13.1 \\
0.4
\end{tabular}

\begin{tabular}{c}
\hline $\mathbf{9 0} \mathbf{~ m i n}$ \\
\hline 83 \\
18.1 \\
0.59 \\
\hline
\end{tabular}

\begin{tabular}{c}
\hline $\mathbf{1 2 0} \mathbf{~}$ in \\
\hline 50 \\
17.2 \\
1.47 \\
\hline
\end{tabular}

\begin{tabular}{c}
\hline $\mathbf{1 5 0} \mathbf{~}$ in \\
\hline 51 \\
15.8 \\
1.59 \\
\hline
\end{tabular}

\begin{tabular}{c}
\hline $\mathbf{1 8 0} \mathbf{~}$ in \\
\hline 57 \\
15.9 \\
0.71 \\
\hline
\end{tabular}

\begin{tabular}{c}
\hline $\mathbf{2 1 0} \mathbf{~}$ in \\
\hline 58 \\
14.3 \\
0.26 \\
\hline
\end{tabular}

\begin{tabular}{c}
\hline $\mathbf{2 4 0}$ in \\
\hline 57 \\
13.2 \\
0.23
\end{tabular}

$\mathrm{GH}$ and cortisol secretion after $1 \mathrm{mg}$ of subcutaneous glucagon. Adequate response: stimulated $\mathrm{GH}$ in adults $>3.75 \mathrm{ng} / \mathrm{mL}$ and cortisol $>20 \mu \mathrm{gg} / \mathrm{dL}$. $\mathrm{GH}$ deficiency in adults $<2.25 \mathrm{ng} / \mathrm{mL}$ at $120 \mathrm{~min}$. $\mathrm{GH}$, growth hormone. 


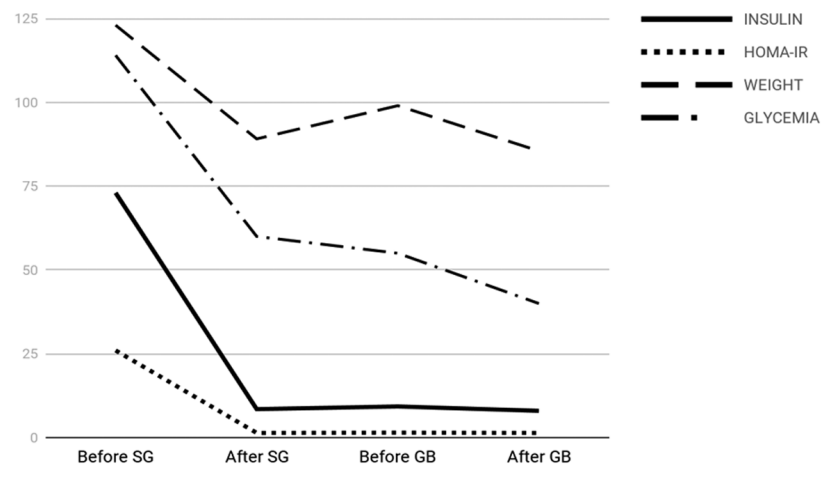

SG: sleeve gastrectomy; GB: gastric bypass; HOMA-IR: homeostatic model assessment for insulin resistance.

\section{Figure 2}

Insulin blood levels (mIU/L), HOMA-IR, weight $(\mathrm{kg})$ and glycemia $(\mathrm{mg} / \mathrm{dL})$ before and 1 year after each bariatric surgery. HOMA-IR levels decrease as the patient loses weight suggesting a restored insulin sensitivity and the start of hypoglycemic episodes.

a blunted growth hormone response to stimulation tests. Assessment is indicated when a history of a hypothalamic-pituitary insult-like surgery occurs, with the insulin tolerance test being the reference standard for establishing the diagnosis (12). As an alternative test, intravenous GHRH plus arginine or injectable glucagon can be used $(12,13)$. In our patient, a glucagon test was performed confirming the diagnosis. A short time after starting treatment with GH, all the episodes disappeared; supporting the notion that hypoglycemia was likely to be related to $\mathrm{GH}$ deficiency.

\section{Declaration of interest}

The authors declare that there is no conflict of interest that could be perceived as prejudicing the impartiality of the research reported.

\section{Funding}

This research did not receive any specific grant from any funding agency in the public, commercial or not-for-profit sector.

\section{Patient consent}

Informed consent has been obtained from the patient for publication of the case report and accompanying images.

\section{Author contribution statement}

One of the authors (Silvia Pellitero) is the main physician of the patient.

\section{References}

1 Nyhan WL, Kölker S \& Hoffmann GF. Work-up of the patient with hypoglycemia. In Inherited Metabolic Diseases, 2nd ed., pp. 101-106. Eds G Hoffmann, J Zschocke \& W Nyhan. Berlin: Springer, 2017.

2 Bansal N \& Weinstock RS. Non-diabetic hypoglycemia. In Endotext [Internet], Updated 2020 May 20. Eds KR Feingold, B Anawalt, A Boyce, G Chrousos, W W de Herder, K Dungan, A Grossman, JM Hershman, J Hofland, G Kaltsas et al. South Dartmouth: Endotext, 2017. (available at: https://www.ncbi.nlm.nih.gov/books/ NBK355894/)

3 Singh E \& Vella A. Hypoglycemia after gastric bypass surgery. Diabetes Spectrum 201225 217-221. (https://doi.org/10.2337/diaspect.25.4.217)

4 Millstein R \& Lawler HM. Hypoglycemia after gastric bypass: an emerging complication. Cleveland Clinic Journal of Medicine $2017 \mathbf{8 4}$ 319-328. (https://doi.org/10.3949/ccjm.84a.16064)

5 Lee CJ, Brown TT, Schweitzer M, Magnuson T \& Clark JM. The incidence and risk factors associated with developing symptoms of hypoglycemia after bariatric surgery. Surgery for Obesity and Related Diseases 201814 797-802. (https://doi.org/10.1016/j. soard.2018.01.028)

6 Halperin F, Patti ME, Skow M, Bajwa M \& Goldfine AB. Continuous glucose monitoring for evaluation of glycemic excursions after gastric bypass. Journal of Obesity 20112011 869536. (https://doi org/10.1155/2011/869536)

7 Khalaf KI \& Taegtmeyer H. Clues from bariatric surgery: reversing insulin resistance to heal the heart. Current Diabetes Reports 201313 245-251. (https://doi.org/10.1007/s11892-013-0364-1)

8 Tang Q, Li X, Song P \& Xu L. Optimal cut-off values for the homeostasis model assessment of insulin resistance (HOMA-IR) and pre-diabetes screening: developments in research and prospects for the future. Drug Discoveries and Therapeutics 20159 380-385. (https:// doi.org/10.5582/ddt.2015.01207)

9 Wallace TM, Levy JC \& Matthews DR. Use and abuse of HOMA modeling. Diabetes Care 200427 1487-1495. (https://doi. org/10.2337/diacare.27.6.1487)

10 Berryman DE \& List EO. Growth hormone's effect on adipose tissue: quality versus quantity. International Journal of Molecular Sciences 2017 18 1621. (https://doi.org/10.3390/ijms18081621)

11 Pellitero S, Olaizola I, Alastrue A, Martínez E, Granada ML, Balibrea JM, Moreno P, Serra A, Navarro-Díaz M, Romero R, et al. Hypogonadotropic hypogonadism in morbidly obese males is reversed after bariatric surgery. Obesity Surgery 201222 1835-1842. (https://doi.org/10.1007/s11695-012-0734-9)

12 Melmed S. Pathogenesis and diagnosis of growth hormone deficiency in adults. New England Journal of Medicine 2019380 2551-2562. (https://doi.org/10.1056/NEJMra1817346)

13 Casanueva FF, Castro AI, Micic D, Kelestimur F \& Dieguez C. New guidelines for the diagnosis of growth hormone deficiency in adults. Hormone Research 200971 (Supplement 1) 112-115. (https://doi. org/10.1159/000178051)

Received in final form 8 February 202

Accepted 2 March 2021 